\title{
ANÁlise DA DINÂMICA DA COBERTURA VEGETAL DE CURITIBA, PR (DE 1986 A 2004), UTILIZANDO IMAGENS LANDSAT TM ${ }^{1}$
}

\author{
Carolina Haddad Souza Dias Vieira² e Daniela Biondi ${ }^{3}$
}

\begin{abstract}
RESUMO - O objetivo deste estudo foi fazer uma análise da dinâmica da cobertura vegetal de Curitiba, PR, por meio da manipulação de imagens Landsat TM. Para isso, foram utilizadas duas imagens Landsat TM, sendo uma de 2004 e outra de 1986, que foram georreferenciadas, classificadas e processadas, a fim de se obter o mapa de cobertura vegetal das duas datas. Foram analisados aspectos quantitativos, bem como a distribuição da cobertura vegetal pelas regionais administrativas da cidade nas duas datas. A cobertura vegetal diminuiu em todas as regionais, como resultado do crescimento urbano, principalmente nas áreas de menor densidade urbana e maior quantidade de cobertura vegetal. Dessa forma, a urbanização expandiu-se para além das áreas de ocupação tradicionais. A regional que apresentou maior diminuição de cobertura vegetal foi a Pinheirinho e a que teve menor diminuição, a Matriz. Foi possível identificar maior carência de cobertura vegetal justamente nas áreas onde a ocupação urbana se faz mais presente. Tal informação pode ser útil ao planejamento de áreas verdes ou à arborização urbana, contribuindo como subsídio para o direcionamento das ações a serem realizadas, ao indicar potencialidades, vocações, carências e necessidades das diversas regiões da cidade.
\end{abstract}

Palavras-chave: Áreas verdes, arborização urbana, sensoriamento remoto.

\section{ANALISYS OF LAND COVER CHANGE IN THE MUNICIPALITY OF CURITIBA, STATE OF PARANÁ - BRAZIL, FROM 1986 TO 2004, USING LANDSAT-TM IMAGERY}

\begin{abstract}
In this essay we present the results of an analysis of land cover change for the municipality of Curitiba, the capital of the state of Paraná, Brazil, using remote sensing data. Two Landsat TM images were used: a 1986 and a 2004, which were georeferenced, classified and processed, in order to obtain the vegetation maps for both dates. Quantitative aspects were analyzed, as well as the distribution of the vegetation areas over the administrative districts of Curitiba. The green areas decreased in all districts, as a result of the urban growth, mainly in areas of lower urban density and higher percentage of vegetation, i.e., the urbanization expanded beyond the traditional areas of occupation. The district that presented the greatest reduction in green areas was Pinheirinho; and the one with the least reduction was Matriz. It was possible to identify a lack of green areas where the urban occupation was more intense. This information can be useful for the planning of green areas or street tree planting, for mitigating those environmental impacts.
\end{abstract}

Keywords: Green areas, Urban Forests and Remote Sensing.

\footnotetext{
${ }^{1}$ Recebido em 22.05.2007 e aceito para publicação em 19.05.2008.

${ }^{2}$ Programa de Pós-Graduação em Ciências Florestais da UFPR. E-mail:<carolinahaddad@gmail.com>.

${ }^{3}$ Departamento de Ciências Florestais da Universidade Federal do Paraná (UFPR), Curitiba-PR. E-mail: <dbiondi@ufpr.br>.
} 


\section{INTRODUÇÃO}

Há apenas cinco décadas, o Brasil agrícola se transformou num país urbano. Atualmente, a grande maioria da sua população habita cidades, mas essa acelerada urbanização não aconteceu sem deixar seqüelas e problemas para o futuro. Hoje, um dos principais desafios é interromper o processo de degradação ambiental nas cidades brasileiras, sobretudo nas metrópoles (DOURADO, 1997).

A crescente exploração predatória dos recursos naturais, a diminuição acelerada de recursos animais e vegetais, a degradação do ambiente humano e a perda da qualidade de vida levaram ao questionamento dos estilos de desenvolvimento que o homem vem adotando com o passar dos anos. Assim, é necessário o repensar da sociedade, com o reordenamento das prioridades humanas, a solidariedade às gerações futuras e a busca coletiva de soluções aos graves problemas, que já são uma realidade (LORENZUTTI, 2001).

Recentemente, as autoridades mundiais têm-se conscientizado da gravidade da degradação ambiental urbana, e esforços têm sido feitos no intuito de recuperar áreas degradadas e de preservar os remanescentes naturais, sendo comum a inclusão de políticas ambientais nos programas estratégicos de governo.

A cidade de Curitiba tem-se destacado em sua história no contexto nacional, sendo vista por muito tempo e, ainda hoje, como exemplo de desenvolvimento ambientalmente sustentável. Segundo IPPUC (2004a), destaca-se nessa cidade um planejamento focado nas questões ambientais, o que se traduz, entre outras coisas, em elevados índices de áreas verdes por habitante.

Esses índices, no entanto, não determinam por si só a qualidade das áreas verdes urbanas e por sua eficiência ambiental. Constituindo uma informação quantitativa, não expressam como essas áreas verdes se encontram, como são utilizadas e como ocorre a sua distribuição dentro da cidade. Segundo Milano (1990), o conhecimento sobre a forma, a qualidade e a distribuição dessas áreas é fundamental para a sua avaliação. Além disso, a maioria das definições de áreas verdes urbanas inclui, mesmo que em pequenas proporções, a presença de áreas antropizadas, incluindo, assim, áreas construídas e extrapolando o conceito de espaços naturais e vegetados.

R. Árvore, Viçosa-MG, v.32, n.3, p.479-487, 2008
Há muitas formas de considerar as diferentes áreas verdes existentes no meio urbano, sendo uma delas a que adota o conceito de "cobertura vegetal". Neste estudo, adotou-se esse conceito. Segundo Cavalheiro et al. (1999), cobertura vegetal é a projeção do verde em cartas planimétricas, considerando os espaços livres, os espaços construídos e os espaços de integração, além das Unidades de Conservação e da zona rural. Essa terminologia se mostra mais adequada, pois, segundo Costa (2004), é mais abrangente e engloba várias categorias de áreas verdes.

Dessa forma, mostram-se importantes o controle e o monitoramento das áreas verdes urbanas, principalmente como suporte à implementação de políticas de crescimento urbano ambientalmente sustentável, incluindo o planejamento urbano e de áreas verdes. Assim, o objetivo deste estudo foi fazer uma análise da dinâmica da cobertura vegetal de Curitiba, PR, por meio de imagens Landsat TM, observando-se a sua distribuição pelo território da cidade.

\section{MATERIAL E MÉTODOS}

\subsection{Caracterização da Área de Estudo}

O Município de Curitiba localiza-se na Região Sul do Brasil e está situado no leste do Estado do Paraná, do qual é a capital, na latitude $25^{\circ} 25^{\prime} 40^{\prime \prime} \mathrm{S}$ e longitude 49 $16^{\prime} 23^{\prime \prime} \mathrm{W}$. A altitude média é de 934,6m acima do nível do mar e a área do município, de 432,17 km², com extensão de $35 \mathrm{~km}$ no sentido norte-sul e $20 \mathrm{~km}$ no sentido lesteoeste. É a cidade-pólo da Região Metropolitana homônima, atualmente composta por 26 municípios, com área de $15.622,33 \mathrm{~km}^{2}$ e população de 2.768 .394 pessoas. Tem como limites os municípios de Colombo e Almirante Tamandaré, ao norte; Campo Magro, a noroeste; Campo Largo, a oeste; Araucária, a sudoeste; Fazenda Rio Grande, ao sul; São José dos Pinhais, a leste; e Pinhais, a nordeste (IPPUC, 2004).

A cidade está situada no Primeiro Planalto Paranaense e possui topografia ondulada de colinas suavemente arredondadas, caracterizada por uma série de terraços escalonados dispostos em intervalos altimétricos. Segundo a classificação de Köppen, a cidade de Curitiba se localiza em região climática do tipo $\mathrm{Cfb}$, com clima temperado (ou subtropical) úmido, mesotérmico, sem estação seca, com verões frescos e invernos com geadas freqüentes (IPPUC, 2004). 
Quanto à vegetação, Curitiba situa-se na região de ocorrência da Floresta Ombrófila Mista e da Estepe Gramíneo-Lenhosa(VELOSOFILHO etal., 1991). Segundo Hardt (2000), incluindo a vegetação introduzida, 62,81\% do território era composto por áreas permeáveis, formadas, em grande parte, por áreas verdes, que correspondiam a 56,83\% do município; as áreas com vegetação não arbórea compreendiam 43,24\%, enquanto as com cobertura arbórea estavam presentes em 13,59\% da cidade.

No que se refere ao meio ambiente, o total de área verde disponível na cidade, segundo a apuração da Secretaria Municipal de Meio Ambiente (SMMA) de 2000, era de $77.901 .198,20 \mathrm{~m}^{2}$, e o índice de cobertura vegetal, de 49,08 $\mathrm{m}^{2} / \mathrm{hab}$. Segundo levantamento da mesma Secretaria, no mesmo ano, o município contava com 30 unidades de parques e bosques, 11 núcleos ambientais, cinco jardins ambientais, 54 largos, 15 eixos de animação, 393 praças e 330 jardinetes (IPPUC, 2004).

O Município de Curitiba, hoje, é composto por 75 bairros, divididos em nove regionais administrativas, que são: Bairro Novo, Boa Vista, Boqueirão, Cajuru, CIC, Matriz, Pinheirinho, Portão e Santa Felicidade (IPPUC, 2006).

Segundo dados do Censo do IBGE de 2000 (IBGE, 2004), a população de Curitiba nesse ano era de 1.587.315 habitantes. A densidade demográfica no mesmo ano, de acordo com Ippuc (2004), era de $3673 \mathrm{hab} / \mathrm{km}^{2}$. Em 1986, a estimativa é de 1.174.207 habitantes e, para 2004, de 1.727.010 habitantes (IPPUC, 2006).

\subsection{Métodos}

Neste estudo foram escolhidas duas imagens Landsat TM, uma de 1986 e outra de 2004, que foram recortadas, a fim de abranger o Município de Curitiba.

Fez-se georreferenciamento das duas imagens, pelo programa ENVI 4.1., pelo modelo polinomial de primeiro grau e reamostragem por convolução cúbica, adotando-se a projeção UTM SAD-69 (Fuso 22) e resolução espacial de $30 \mathrm{~m}$. Os pontos de controle e verificação foram marcados com o auxílio de um mapa de Curitiba e de bases de dados vetoriais georreferenciados (sistema viário, bairros, hidrografia e quadras). A utilização de mapas e bases de dados vetoriais se mostrou suficiente para a marcação dos pontos de controle e verificação, bem como para a identificação da área de estudo em sua totalidade, não tendo sido necessário que se fizessem levantamentos de campo. Martins et al. (2002), por sua vez, que também utilizaram imagem Landsat TM em seu estudo para diagnóstico ambiental de fragmentos florestais naturais em Lagoa da Confusão, TO, optaram por efetuar trabalhos de campo, percorrendo a área de estudo, a fim de se confirmarem as diferentes feições fisionômicas e os pontos de controle.

Em seqüência, foi feita a classificação supervisionada das imagens corrigidas, utilizando-se o programa Multispec, a fim de se obterem imagens mais simplificadas para a análise da cobertura vegetal. Na imagem Landsat de 2004 foram adotadas sete classes: "mata”, "vegetação", “água profunda”, “água rasa/ solo úmido", "urbano", "construções" e "solo exposto". Já, na imagem Landsat de 1986, utilizaram-se nove classes: "mata", "sombra de mata", "vegetação", "água profunda", “água rasa/solo úmido”, “urbano”, “construções”, “solo exposto" e "solo 2".

A partir das imagens classificadas, foram gerados mapas de cobertura vegetal dos anos de 1986 e 2004 em Curitiba, com divisão em regionais administrativas. Todos os procedimentos necessários à obtenção dos mapas e à análise de dados foram feitos no Sistema de Informações Geográficas (SIG) ArcGis 9.1. A escolha desse SIG como ferramenta para confecção de mapas mostrou-se adequada, tendo sido eficiente no cruzamento de informações para a realização das análises. NOGUEIRA et al. (2002) também utilizaram o Arcview para produção de mapas e processamento de dados, na escolha de locais para instalação de torres de detecção de incêndio em Belo Oriente, MG.

As imagens, que estavam em formatoraster, foram convertidas para o formato vetorial. Em seguida, por meio de uma base de dados vetoriais georreferenciada dos bairros de Curitiba, de 2002, foi gerada uma nova base com os limites do município, com a qual foi feito um recorte nas imagens, a fim de se obterem, nelas, os limites do território municipal.

Em seguida, a classificação das imagens foi reduzida a quatro classes: "cobertura vegetal" (resultante do agrupamento das classes "mata", "sombra de mata" e vegetação), "corpos hídricos" (resultante do agrupamento das classes "água profunda” e "água rasa/solo úmido"), "urbano" (resultante do agrupamento das classes "urbano" e "construções") e "solo exposto"

R. Árvore, Viçosa-MG, v.32, n.3, p.479-487, 2008 
(resultante do agrupamento das classes "solo exposto" e "solo 2"). Foram obtidas as áreas referentes a cada uma das quatro classes e, a partir desses dados, foram gerados os mapas de cobertura vegetal para as duas datas.

Com o objetivo de fazer uma análise da distribuição da cobertura vegetal no território do município, foi gerado, a partir da base de dados vetorial dos bairros, um mapa de regionais administrativas, a saber: Bairro Novo, Boa Vista, Boqueirão, Cajuru, CIC, Matriz, Pinheirinho, Portão e Santa Felicidade. Foram analisados a distribuição da cobertura vegetal pelas regionais e o porcentual relativo à cobertura vegetal no território da regional em questão. Os resultados foram relacionados e discutidos com base na direção política, econômica e social dos gestores da cidade durante os períodos analisados.

\section{RESULTADOS E DISCUSSÃO}

\subsection{Distribuição do Município em Regionais}

No quadro 1, apresentam-se as áreas total e das regionais administrativas do Município de Curitiba, obtidas por meio das imagens.

A área total do município encontrada foi de 434,54 $\mathrm{km}^{2}$, valor da mesma ordem de grandeza ao encontrado pelo IBGE (2006), de 434,97 km², e maior que o obtido pelo Ippuc (2004b), que é de $432,17 \mathrm{~km}^{2}$. Entre as regionais administrativas, a que possui maior área é a Santa Felicidade, que contém $15 \%$ do município, seguida da Boa Vista com $14,4 \%$ e da CIC, com $13,80 \%$. A de menor área é a Portão com 7,8\%, seguida da Cajuru, com $8,2 \%$ e da Matriz com $8,3 \%$. De forma geral, pode-se dizer que a divisão do município em regionais é homogênea, não apresentando diferenças grandes entre as suas áreas. A Figura 1 ilustra a divisão territorial do município em regionais.

Quadro 1 - Área municipal total e por regionais administrativas de Curitiba

Table 1 - Regionais administrativas de Curitiba

\begin{tabular}{lcc}
\hline \multicolumn{1}{c}{ Regional } & Área (ha) & Área $(\%)$ \\
\hline CIC & $5.997,23$ & 13,80 \\
Bairro Novo & $4.499,61$ & 10,35 \\
Boa Vista & $6.250,75$ & 14,38 \\
Boqueirão & $3.982,34$ & 9,16 \\
Cajuru & $3.566,68$ & 8,21 \\
Matriz & $3.595,22$ & 8,27 \\
Pinheirinho & $5.665,08$ & 13,04 \\
Portão & $3.381,55$ & 7,78 \\
Santa Felicidade & $6.515,18$ & 14,99 \\
TOTAL & $43.453,65$ & 100,00 \\
\hline
\end{tabular}

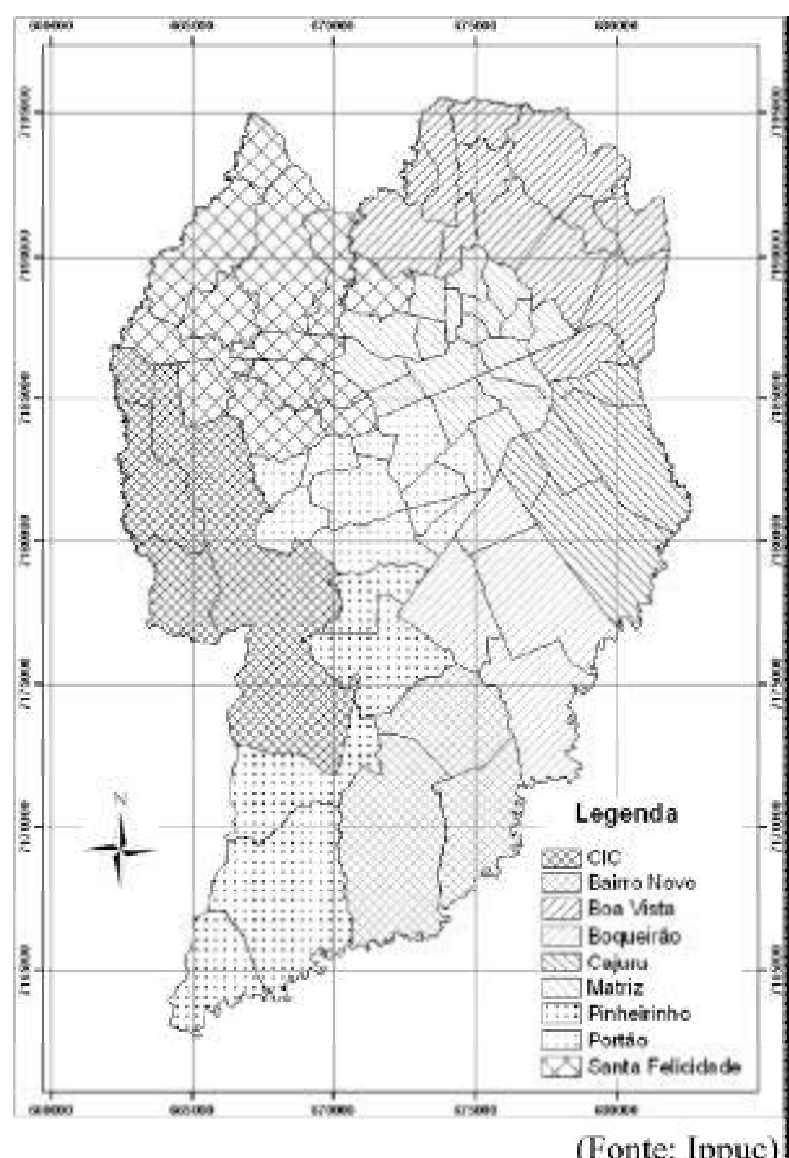

(Fonte: Ippuc)

Figura 1 - Administrative districts of Curitiba.

Figure 1-Total municipal area and for regional administrations of Curitiba.

\subsection{Análise Temporal}

A análise temporal se trata de uma análise comparativa dos anos de 1986 e 2004. No Quadro 2, apresentam-se os valores comparativos da distribuição por classes do território municipal de Curitiba e na Figura 2, os mapas de cobertura vegetal para as mesmas datas.

A classe "cobertura vegetal" do Município de Curitiba perdeu sua representatividade no período de 1986 a 2004. Se em 1986 ela ocupava 39\% do território municipal $\left(169,25 \mathrm{~km}^{2}\right)$, em 2004 passou a ocupar $30 \%$ do município $\left(129,95 \mathrm{~km}^{2}\right)$. Esse fato foi devido, principalmente, ao aumento da população e, conseqüentemente, o crescimento das áreas urbanas. 
Quadro 2 - Distribuição da área municipal por classes Table 2 - Distribution of the Municipal area per classes

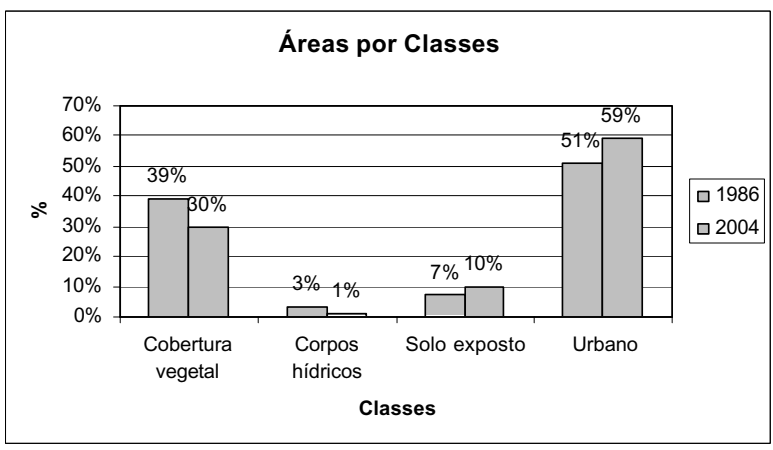

No período de 1980 a 1991, a Região Metropolitana de Curitiba (RMC) registrou uma das maiores taxas de crescimento do país, chegando a 1.313 .374 pessoas em 1991, com uma densidade demográfica de 3.037 hab./ $\mathrm{km}^{2}$. Em 1997 esses números subiram para 1.516.457 habitantes e densidade demográfica de $3.507 \mathrm{hab} . / \mathrm{km}^{2}$. Durante esse período, a taxa de crescimento da população foi de 3,31\% ao ano (GEISSLER, 2004).

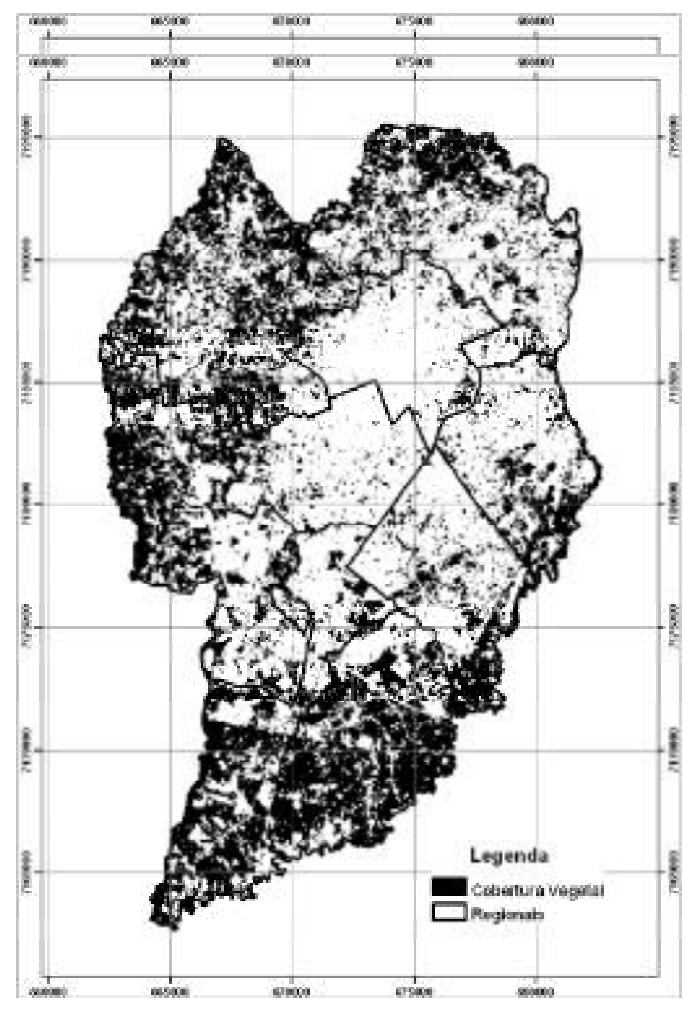

No ano 2000, a RMC contava com uma população de 2.768.394 habitantes, com 57,34\% dessas pessoas residindo no município-sede. Com a população totalmente urbana, o Município de Curitiba já representava $16,6 \%$ da população do Paraná e $0,93 \%$ da população do Brasil. Segundo dados do IBGE, entre 1991 e 2000 a população de Curitiba teve uma taxa média de crescimento anual de $2,20 \%$, passando de 1.315 .035 para 1.587.315 pessoas (IMAP, 2006).

Embora não tenha havido censos nos anos de interesse desta pesquisa, segundo estimativas do IBGE, em 1986 o Município de Curitiba já possuía 1.174.207 habitantes. E, em 2004, essa população alcançou 1.727.010 habitantes (IPPUC, 2006). Dessa forma, a diminuição da cobertura vegetal ocorrida no período estudado se deu em função do grande crescimento urbano representado por esses índices, que ocorreu em todo o município, e não apenas nas regiões de urbanização já consolidada. No Quadro 3, apresenta-se a distribuição da cobertura vegetal pelas regionais administrativas, que comprova esse aspecto.

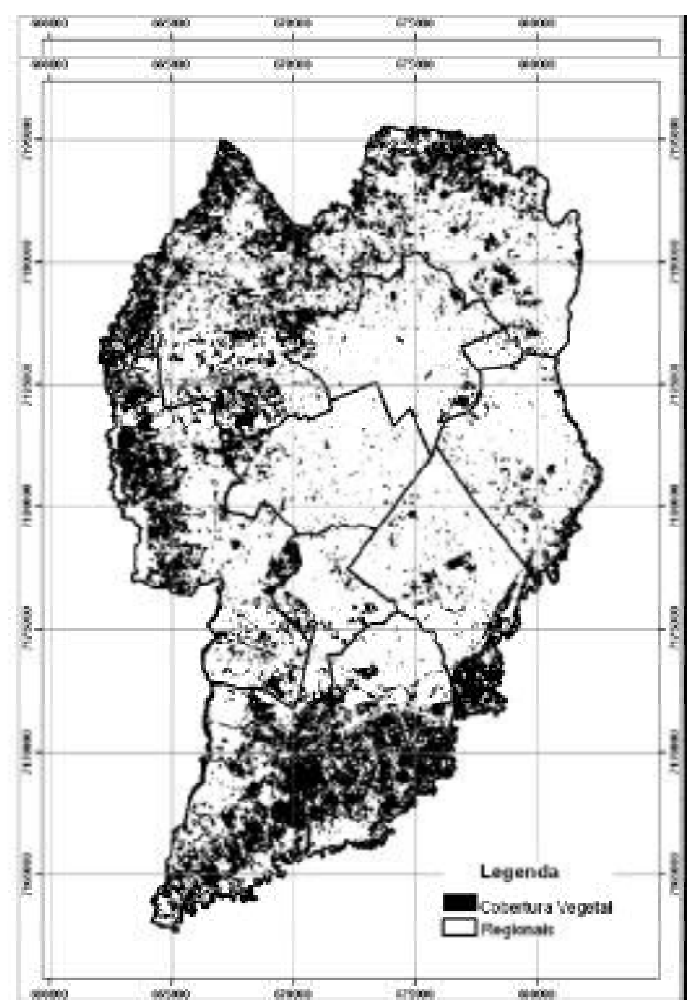

Figura 1 - Mapa de cobertura vegetal de Curitiba em 1986 e 2004, respectivamente.

Figure 1 -Vegetation cover map of Curitiba in 1986 and 2004, respectively. 
Quadro 3 - Evolução da distribuição da cobertura vegetal pelas regionais administrativas

Table 3 - Vegetation cover distribution across the regional administrations

\begin{tabular}{l|rr}
\hline \multirow{2}{*}{ Regionais } & \multicolumn{2}{|c}{ Distribuição da Cobertura Vegetal (\%) } \\
\cline { 2 - 3 } & 1986 & \multicolumn{2}{c}{2004} \\
\hline CIC & 16,29 & 16,32 \\
Bairro Novo & 16,53 & 17,11 \\
Boa Vista & 13,45 & 14,26 \\
Boqueirão & 6,54 & 6,23 \\
Cajuru & 5,99 & 3,44 \\
Matriz & 2,17 & 2,36 \\
Pinheirinho & 17,04 & 16,80 \\
Portão & 2,46 & 1,99 \\
S. Felicidade & 19,54 & 21,46 \\
\hline \multicolumn{1}{c}{ Total } & 100,00 & 100,00 \\
\hline
\end{tabular}

Por esses dados (Quadro 3), percebe-se que a cobertura vegetal, que já se apresentava mal distribuída, teve um aumento dessa característica. As cinco regionais com maior representatividade permaneceram as mesmas (Santa Felicidade, Pinheirinho, Bairro Novo, CIC e Boa Vista), apenas alterando a ordem entre si. A regional Santa Felicidade continuou sendo a de maior representatividade, mas houve pequeno aumento no somatório dos porcentuais de cobertura vegetal dessas cinco regionais, que correspondem a $66,56 \%$ do território do município. Se em 1986 essas regionais representavam, juntas, 82,84\% da classe em questão, em 2004 esse índice subiu para $85,98 \%$, o que comprova um aumento da má distribuição dessa classe pelo município.

As regionais com menor participação no total de cobertura vegetal em 1986 eram, em ordem crescente, a Matriz (com 2,17\%), seguida da Portão (com 2,46\%) e da Cajuru (com 5,99\%). Estas continuaram constituindo o grupo de menor participação em 2004, com a regional Portão apresentando 1,99\%, a Matriz com 2,36\% e a Cajuru com 3,44\% do total de "cobertura vegetal" do município. $\mathrm{O}$ fato de essas serem as regionais com menor índice de cobertura vegetal se explica pelo fato de, segundo Vieira (2006), serem regionais com altos índices de urbanização.

No caso das regionais Matriz e Portão, estas já eram bastante urbanizadas em 1986, fato que se manteve até 2004. E, no caso da regional Cajuru, esta não era tão urbanizada em 1986, mas apresentou um dos maiores aumentos dessa característica, tornando-se uma das regionais mais urbanizadas (VIEIRA, 2006).
Em todas as regionais houve decréscimo na quantidade de cobertura vegetal de seu território e, conseqüentemente, de seus índices porcentuais referentes a essa classe. Essa diminuição foi chamada, aqui, de "diminuição porcentual relativa". Esse índice foi obtido dividindo-se a diferença de área de cobertura vegetal entre 1986 e 2004 pela área, ou seja, de 1986 - o que dá uma idéia da variação proporcional da cobertura vegetal em relação à situação inicial. No Quadro 4 são apresentados esses índices, além das áreas absolutas e relativas de cobertura vegetal em 1986 e 2004.

As regionais que sofreram maior diminuição proporcional de cobertura vegetal em seu território foram: Cajuru (com "diminuição porcentual relativa" de 55,91\% da cobertura vegetal de seu território), Portão (com “"diminuição porcentual relativa" de 37,79\%), Boqueirão (com "diminuição porcentual relativa" de $26,86 \%$ ) e Pinheirinho (com "diminuição porcentual relativa" de $24,30 \%$ ), todas elas apresentando índice superior à "diminuição porcentual relativa" total do município, que foi de $23,22 \%$. Dessas, a Cajuru e a Pinheirinho estão entre as regionais que tiveram maior aumento da urbanização no período estudado, o que explica a diminuição de cobertura vegetal. No caso da Pinheirinho, em adição, houve aumento significativo de solo exposto em seu território (VIEIRA, 2006).

Já a regional Portão não teve grande crescimento urbano no período estudado, mas isso se deve ao fato de que essa regional já era, em 1986, bastante urbanizada. Em adição, a taxa de cobertura vegetal dessa regional já era baixa, 12,31\%, de forma que a sua diminuição para $7,66 \%$ representou um índice de diminuição relativo alto, justificando a sua inclusão nesse grupo (VIEIRA, 2006).

Já a regional Boqueirão não apresentou “diminuição porcentual relativa" muito abaixo do índice total do município (14,36\%, quando a do município foi de 15,68\%), e em soma a isso, segundo Vieira (2006), esta já era uma regional com alto índice de urbanização.

No Quadro 5, também se apresenta a evolução da classe "cobertura vegetal" em cada regional administrativa.

Por esse gráfico, nota-se que as regionais com mais e menos quantidade de cobertura vegetal permaneceram basicamente as mesmas, apenas invertendo algumas posições. A regional Pinheirinho foi a que apresentou maior diminuição de cobertura vegetal (vetor mais inclinado), enquanto a Matriz exibiu a menor diminuição (vetor menos inclinado, quase uma linha reta). 
Quadro 4 - Evolução da cobertura vegetal nas regionais administrativas Table 4 -Vegetation cover within the regional administrations

\begin{tabular}{|c|c|c|c|c|c|c|}
\hline \multirow{2}{*}{ Regional } & \multicolumn{2}{|c|}{ Cobertura Vegetal em 1986} & \multicolumn{2}{|c|}{ Cobertura Vegetal em 2004} & \multirow{2}{*}{$\begin{array}{l}\text { Diferença } \\
\text { (ha) }\end{array}$} & \multirow{2}{*}{$\begin{array}{c}\text { Diminuição } \\
\text { Percentual } \\
\text { Relativa (\%) }\end{array}$} \\
\hline & área (ha) & $\%$ da regional & área (ha) & $\%$ da regional & & \\
\hline$\overline{\mathrm{CIC}}$ & $2.757,24$ & 45,97 & $2.120,71$ & 35,36 & $-636,53$ & 23,09 \\
\hline Bairro Novo & $2.797,31$ & 62,17 & $2.222,96$ & 49,40 & $-574,35$ & 20,53 \\
\hline Boa Vista & $2.275,92$ & 36,41 & $1.853,52$ & 29,65 & $-422,40$ & 18,56 \\
\hline Boqueirão & $1.106,52$ & 27,78 & 809,35 & 20,33 & $-297,17$ & 26,86 \\
\hline Cajuru & $1.014,42$ & 28,44 & 447,29 & 12,54 & $-567,14$ & 55,91 \\
\hline Matriz & 366,53 & 10,20 & 306,45 & 8,52 & $-60,08$ & 16,39 \\
\hline Pinheirinho & $2.883,27$ & 50,89 & $2.182,66$ & 38,53 & $-700,61$ & 24,30 \\
\hline Portão & 416,22 & 12,31 & 258,93 & 7,66 & $-157,30$ & 37,79 \\
\hline S. Felicidade & $3.307,88$ & 50,77 & $2.792,64$ & 42,86 & $-515,24$ & 15,58 \\
\hline $\begin{array}{r}\text { Total do } \\
\text { Município }\end{array}$ & $16.925,31$ & & $12.994,50$ & & $-3.930,81$ & 23,22 \\
\hline
\end{tabular}

Quadro 5 - Evolução da cobertura vegetal por regionais administrativas Table 5 - Vegetation cover per regional administration

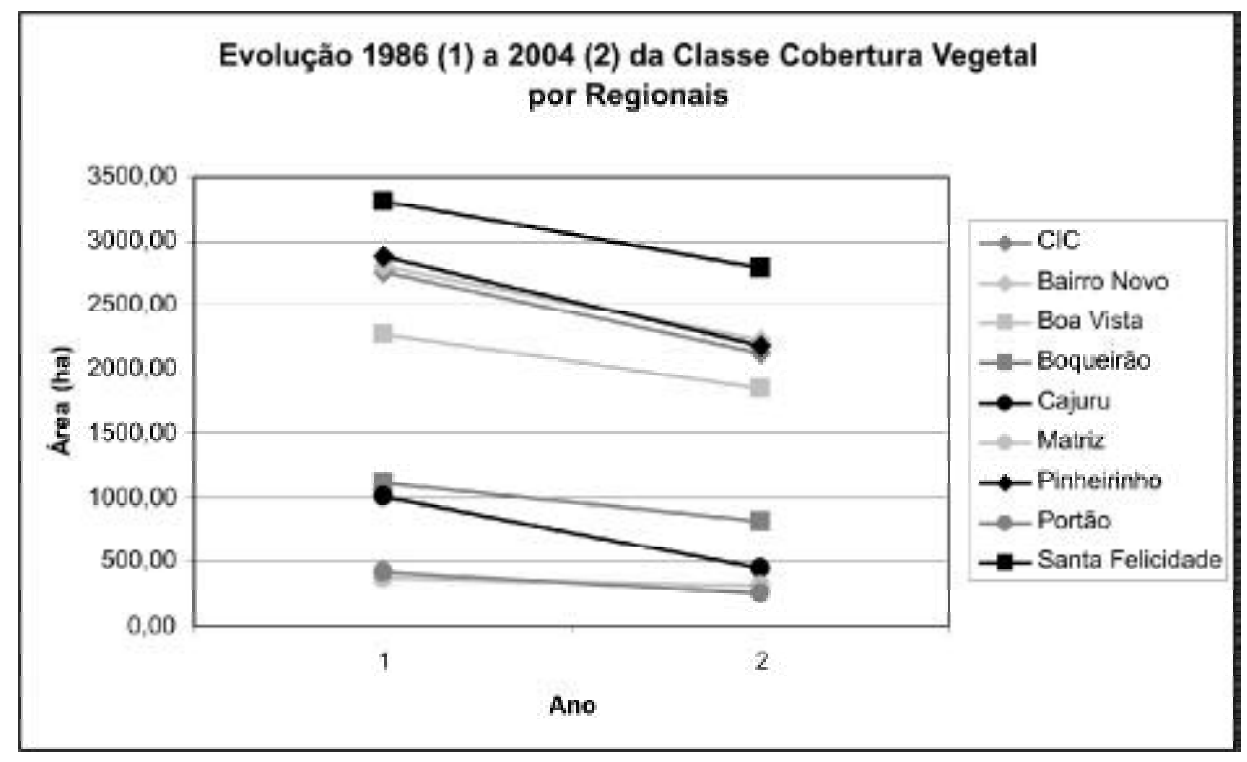

Santa Felicidade, Pinheirinho, Bairro Novo, CIC e Boa Vista formam o grupo das regionais com maior quantidade de cobertura vegetal, tanto em 1986 quanto em 2004. Nessas regionais, entretanto, a diminuição de cobertura vegetal foi mais acentuada (vetores mais inclinados), o que indica que as regionais que apresentavam maior quantidade de cobertura vegetal foram as que sofreram maior diminuição dessa classe. No entanto, Boqueirão, Cajuru, Portão e Matriz formam o grupo das regionais que apresentam, nas duas datas, menores quantidades de cobertura vegetal. E, analogamente, constituem-se nas regionais que apresentaram menor diminuição de cobertura vegetal (vetores menos inclinados). Isso indica a menor diminuição de cobertura vegetal entre as regionais que já apresentavam menor quantidade desta.

A exceção, nesse segundo grupo, fica por conta da regional Cajuru. Nessa, embora a quantidade de 
cobertura vegetal estivesse entre as menores em 1986, sua diminuição foi comparável àquelas das regionais de maior quantidade. Uma explicação para esse fenômeno está no aumento da urbanização nessa regional que, segundo Vieira (2006), pode ser explicado em função de sua localização, próxima às áreas de urbanização mais densa do município. Segundo essa autora, uma "saturação" das áreas de ocupação urbana mais tradicionais pode ter intensificado o processo de urbanização na área contígua, onde se encontra a regional Cajuru, indicando, portanto, que grande parte da pouca cobertura vegetal que existia nessa regional "cedeu" lugar à urbanização que se expandia.

Pode-se dizer, assim, que a cobertura vegetal diminuiu, principalmente, naqueles locais onde ela era mais abundante; e, analogamente, a urbanização aumentou onde ela menos se apresentava. Isso indica que a cobertura vegetal foi substituída pela urbanização em função do processo de crescimento da cidade. Dessa forma, e como já foi visto, a diminuição das quantidades - relativas e absolutas de cobertura vegetal no município é efeito do aumento populacional e crescimento urbano que, apesar das políticas de preservação e controle ambiental, trouxeram esse tipo de conseqüências ao cenário da capital.

Apesar da diminuição da cobertura vegetal do município no período estudado, muitos dos esforços das gestões administrativas se apresentaram na intenção de minimizar esses efeitos e compensar suas conseqüências, por meio de políticas de preservação de áreas verdes, que ganhou impulso com a criação da Secretaria Municipal do Meio Ambiente (SMMA) e o mapeamento de áreas verdes feito em 1987. Nesse sentido, destaca-se a criação de parques e bosques, como parte das políticas de meio ambiente (MENEZES, 1996; OBA, 1998; IMAP, 2006).

\section{CONCLUSÕES E RECOMENDAÇÕES}

A cobertura vegetal diminuiu de $39 \%$ para $30 \%$ no território do Município de Curitiba, de 1986 a 2004, como resultado do processo de crescimento urbano. Essa diminuição se deu em todas as regionais administrativas.

As regionais com maior representatividade no total da cobertura vegetal do município permaneceram as mesmas, assim como as regionais com maior parcela de seus próprios territórios ocupadas por cobertura vegetal.

A cobertura vegetal já era mal distribuída pelo território do município em 1986, tendo aumentado essa característica em 2004.

R. Árvore, Viçosa-MG, v.32, n.3, p.479-487, 2008
O crescimento urbano se expandiu para além das áreas tradicionalmente mais densas, densificando-se nelas e acentuando-se nas áreas contíguas a elas, numa resposta à saturação dessas áreas, ocasionando, nesses locais, uma grande diminuição da cobertura vegetal. Nesse sentido, destaca-se a grande mudança ocorrida no cenário da regional Cajuru, que apresentou grande aumento de sua urbanização, que já era bastante relevante, e grande diminuição de sua cobertura vegetal, que já se apresentava bastante reduzida em 1986.

Foi possível identificar maior carência de cobertura vegetal em determinadas áreas, justamente naquelas em que a ocupação urbana se faz mais presente. Dessa forma, é necessário que haja uma preocupação por parte das gestões públicas em relação a essas áreas. Essa informação pode ser útil ao planejamento de áreas verdes ou arborização urbana (áreas verdes, públicas e privadas, somadas à arborização de ruas), contribuindo como subsídio para o direcionamento das ações a serem realizadas.

A abordagem da divisão territorial do município por regionais administrativas foi uma escolha que se mostrou procedente, tendo incluído um aspecto associado às gestões públicas no estudo.

Os resultados podem, ainda, servir de subsídio a estudos posteriores, como associando a distribuição espacial da cobertura vegetal ao uso e ocupação do solo e aprofundando o estudo dos processos causadores de mudanças no território municipal.

\section{REFERÊNCIAS}

CAVALHEIRO, F.; NUCCI, J. C.; GUZZO, P.; ROCHA, Y. T. Proposição de Terminologia para o Verde Urbano. In: Boletim Informativo da SBAU. Ano VII, n ${ }^{\circ} 3$ - jul/ago/set de 1999. Rio de Janeiro-RJ: SBAU, 1999.

COSTA, F. P. S. Evolução Urbana e da Cobertura Vegetal de Piracicaba - SP (1940 - 2000). Piracicaba-SP: 2004. Dissertação (Mestrado em Ecologia de Agroecossistemas). Escola Superior de Agricultura, Universidade de São Paulo. 96 f.

DOURADO, G. M. Visões de Paisagem: Um panorama do paisagismo contemporâneo no Brasil. São Paulo-SP: [s.n.], 1997. 319p. 
HARDT, L.P.A. Subsídios à Gestão da Qualidade da Paisagem Urbana: Aplicação a Curitiba-PR. Curitiba-PR: 2000. Tese (Doutorado em Engenharia Florestal), Setor de Ciências Agrárias, Universidade Federal do Paraná. 323f.

IBGE - Instituto Brasileiro de Geografia e Estatística. Disponível em: http://www.ibge.gov.br. Acesso em: out. 2004.

IPPUC - Instituto de Pesquisa e Planejamento Urbano de Curitiba. Disponível em: http:// www.ippuc.org.br. Acesso em: ago. 2006

IPPUC. Curitiba em Dados 2004. CD-ROM. Curitiba-PR: Ippuc, 2004.

LORENZUTTI, F. Parque Estadual da Fonte Grande. Vitória-ES: 2001. Monografia (Graduação em Arquitetura e Urbanismo) - Centro de Ciências Humanas, Universidade Federal do Espírito Santo. 81f.

MARTINS, I. C. M.; SOARES, V.P.; SILVA, E.; BRITES, R.S. Diagnóstico Ambiental no Contexto da Paisagem de Fragmentos Florestais Naturais "Ipucas" no Município de Lagoa da Confusão, Tocantins. In: Revista Árvore, v. 26, n.3, p.299-309, 2002.
MILANO, M.S. Planejamento da Arborização Urbana: Relações entre áreas verdes e ruas arborizadas. In: ENCONTRO NACIONAL SOBRE ARBORIZAÇÃO URBANA, III (1990: Curitiba-PR). Anais. FUPEF / UFPR: 1990. p. 60-71

NOGUEIRA, G. S.; RIBEIRO, G. A.; RIBEIRO, C. A. A. S.; SILVA, E.P. Escolha de Locais para Instalação de Torres de Detecção de Incêndio com Auxílio do SIG. Revista Árvore, Viçosa-MG, v. 26, n.3, p. 363-369, 2002.

VELOSO FILHO, H. P.; RANGEL, A. L. R.; LIMA, J.C.A. Classificação da Vegetação Brasileira Adaptada a um Sistema Universal. Rio de Janeiro-RJ: IBGE, 1991.

VIEIRA, C. H. S. D. Estudo da Dinâmica de Cobertura Vegetal de Curitiba-PR com Uso de Imagens Digitais. CuritibaPR: 2006. Dissertação (Mestrado em Engenharia Florestal), Setor de Ciências Agrárias, Universidade Federal do Paraná. 